\title{
XPS Study of the Effect of Ar-Ion Bombardment and Aging on Surface Properties of Superionic Conducting Glass $(\mathrm{CuI})_{0.3}\left(\mathrm{Cu}_{2} \mathrm{O}\right)_{0.35}\left(\mathrm{MoO}_{3}\right)_{0.35}$
}

\author{
Shigeru Suzuki ${ }^{\dagger}$, Masatoshi Saito, Shinchul C. Kang, \\ Kallarackel T. Jacob ${ }^{\dagger \dagger}$ and Yoshio Waseda \\ Institute for Advanced Materials Processing, Tohoku University, Katahira, \\ Sendai 980-8577, Japan
}

\begin{abstract}
XPS analysis has been used for characterizing the effects of argon-ion bombardment and aging at room temperature on the surface properties of the superionic conducting glass having the composition $(\mathrm{CuI})_{0.3}\left(\mathrm{Cu}_{2} \mathrm{O}\right)_{0.35}\left(\mathrm{MoO}_{3}\right)_{0.35}$. Copper and molybdenum ions in this particular glass are found to be significantly reduced by argon-ion bombardment, $\mathrm{Cu}^{2+}$ to $\mathrm{Cu}^{0}$ and $\mathrm{Mo}^{6+}$ to $\mathrm{Mo}^{4+}$. The chemical change is attributed to preferential sputtering of iodine and oxygen from the surface of the glass. The concentration of copper on the surface increases and that of molybdenum decreases with aging at room temperature. From aging curves, the diffusion coefficient of copper is estimated to be of the order of $10^{-23} \mathrm{~m}^{2} \cdot \mathrm{s}^{-1}$.
\end{abstract}

(Received April 16, 1998; In Final Form June 11, 1998)

Keywords: $X$-ray photoelectron spectroscopy, superionic conducting glass, $(\mathrm{CuI})-\left(\mathrm{Cu}{ }_{2} \mathrm{O}\right)-\left(\mathrm{MoO}_{3}\right)$ system, diffusion coefficient of copper, ion bombardment

\section{Introduction}

A number of glasses exhibiting superionic conductivity, especially glasses based on silver halides, have been discovered and their properties have been investigated by a variety of methods ${ }^{(1)-(3)}$. Recently, $\mathrm{Cu}^{+}$ion conducting glasses have interest because of their higher electrical conductivity in comparison with systems containing $\mathrm{Ag}^{+}$. Transport and structural properties of the glasses containing $\mathrm{Cu}^{+}$have measured ${ }^{(4)-(6)}$. The $\mathrm{CuI}-\mathrm{Cu}_{2} \mathrm{O}-\mathrm{MoO}_{3}$ glass, which was first synthesized by Machida et al.$^{(7)(8)}$, is one of the typical superionic conducing glasses showing high ionic conductivity at room temperature. The local structures in the $(\mathrm{CuI})_{0.3}\left(\mathrm{Cu}_{2} \mathrm{O}\right)_{0.35}\left(\mathrm{MoO}_{3}\right)_{0.35}$ glass have been analyzed using anomalous $\mathrm{X}$-ray scattering ${ }^{(9)}$. The results provide information on the coordination of ions around $\mathrm{Cu}^{+}$and $\mathrm{Mo}^{+}$. Local ordering in the glassy oxide matrix produces an environment for copper ions which is similar to that in molten CuI.

In addition to the structural aspects of the superionic conducting glasses, the chemical state and concentration of constituent elements in these materials may be of importance. X-ray photoelectron spectroscopy (XPS) is one of the analytical methods for characterizing the chemical state and concentration on the solid surfaces. However, it should be noted that ion bombardment frequently

† Present address: Advanced Technology Research Laboratories, Nippon Steel Corporation, Ida, Nakahara-ku, Kawasaki 211-0035, Japan.

† On sabbatical leave from Materials Research Centre and Department of Metallurgy, Indian Institute of Science, Bangalore 560012 , India. applied in XPS measurements may induce changes in the chemical state and concentration of unstable compounds, as exemplified by the system $\mathrm{K}-\mathrm{Cr}-\mathrm{O}^{(10)}$. Since the $\mathrm{CuI}-\mathrm{Cu}_{2} \mathrm{O}-\mathrm{MoO}_{3}$ glass also has complex composition, it is useful to investigate the chemical state of ions present on the surface of the glass. According to preliminary results, the surface concentration of the superionic conducting $\mathrm{CuI}-\mathrm{Cu}_{2} \mathrm{O}-\mathrm{MoO}_{3}$ glass is considerably different from the bulk concentration, suggesting that the surface concentration of a cleaved surface may change with time. This may be related to the fast migration of ions to the surface from the bulk in the glass. These factors prompted a study of the influence of argon-ion bombardment and aging at room temperature on the chemical state and concentration of species on the surface of the $\mathrm{CuI}-\mathrm{Cu}_{2} \mathrm{O}-\mathrm{MoO}_{3}$ glass. XPS was used for characterizing the behavior of the glass having the composition $(\mathrm{CuI})_{0.3}\left(\mathrm{Cu}_{2} \mathrm{O}\right)_{0.35}\left(\mathrm{MoO}_{3}\right)_{0.35}$.

\section{Experimental}

The $(\mathrm{CuI})_{0.3}\left(\mathrm{Cu}_{2} \mathrm{O}\right)_{0.35}\left(\mathrm{MoO}_{3}\right)_{0.35}$ glass was prepared using a method reported previously ${ }^{(7)}$. High-grade chemical reagents $\mathrm{CuI}, \mathrm{Cu}_{2} \mathrm{O}$ and $\mathrm{MoO}_{3}$ were weighed, thoroughly mixed and then heated in a silica tube under nitrogen gas. After melting at $970 \mathrm{~K}$, the glass was obtained by quenching into ice water. They were cut into small blocks of about $2 \mathrm{~mm}$ diameter and $4 \mathrm{~mm}$ length, which were inserted in a sample holder and cleaved in air just before XPS measurements. Although a sample cleaved under ultra high vacuum was also investigated, the XPS results were fundamentally similar to those of samples cleaved in air. Therefore, the influence of adsorption of gases from air 
on the surface may be insignificant.

XPS measurements were carried out using PHI-5600, in which the incident X-ray beam was $\mathrm{Mg} \mathrm{K} \alpha$. Mainly, $\mathrm{Cu}$ 2p, I 3d, Mo 3d and O 1s XPS spectra were recorded. The energy positions of the spectra were calibrated using $\mathrm{Au} 4 \mathrm{f}$ at $84.0 \mathrm{eV}$. X-ray excited Auger electron spectra for copper were also recorded to study the chemical state of copper ${ }^{(11)(12)}$, since the chemical shift of $\mathrm{Cu} 2 \mathrm{p}$ XPS spectra is very small between $\mathrm{Cu}^{0}$ and $\mathrm{Cu}^{+}$. The effect of aging after cleavage on the surface concentration was investigated by keeping the samples in air at room temperature. Ion bombardment of glass sample by irradiated argon ions of $3 \mathrm{keV}$ was carried out using an attached ion gun.

\section{Results and Discussion}

1. Changes in XPS spectra of the glass $(\mathrm{CuI})_{0.3^{-}}$ $\left(\mathrm{Cu}_{2} \mathrm{O}\right)_{0.35}\left(\mathrm{MoO}_{3}\right)_{0.35}$ caused by argon-ion bombardment

Figure 1(a) shows a $\mathrm{Cu} 2 \mathrm{p}$ XPS spectrum from the glass $(\mathrm{CuI})_{0.3}\left(\mathrm{Cu}_{2} \mathrm{O}\right)_{0.35}\left(\mathrm{MoO}_{3}\right)_{0.35}$ bombarded by argon ions for $600 \mathrm{~s}$, which correspond to a steady-state stage in sputtering profiles. A $\mathrm{Cu}$ XPS spectrum from this glass as cleaved is shown in Fig. 1(b). The $\mathrm{Cu} 2 \mathrm{p}_{3 / 2}$ peak is located at $932.8 \pm 0.3 \mathrm{eV}$ in the both cases, in agreement with the peak energy in several $\mathrm{Cu}^{+}$compounds report$\mathrm{ed}^{(13)}$. Thus, the argon ion bombardment does not appear to affect the peak significantly. A small satellite peak corresponding to $\mathrm{Cu}^{2+}$ is observed in both cases at about $954 \mathrm{eV}$, which suggests the presence of a small amount of $\mathrm{Cu}^{2+}$ ions. The difference in the peak positions of oxide

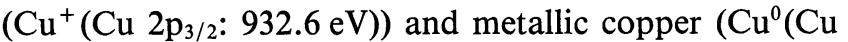
$\left.2 \mathrm{p}_{3 / 2}: 932.7 \mathrm{eV}\right)$ ) is very small. Cu LMM AES spectra are

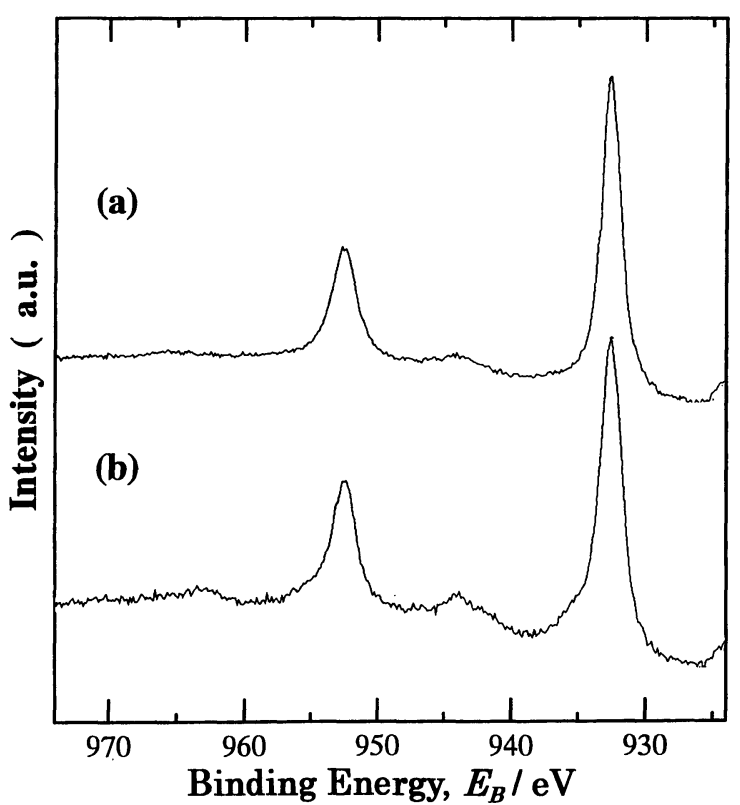

Fig. $1 \mathrm{Cu} 2 \mathrm{p}$ XPS spectra of the $(\mathrm{CuI})_{0.3}\left(\mathrm{Cu}_{2} \mathrm{O}\right)_{0.35}\left(\mathrm{MoO}_{3}\right)_{0.35}$ glass (a) bombarded by argon ions, and (b) cleaved in air. more diagnostic of the reduced state of copper ${ }^{(11)-(13)} . \mathrm{Cu}$ $\mathrm{L}_{3} \mathrm{M}_{45} \mathrm{M}_{45}$ XAES (X-ray excited Auger Electron Spectroscopy) spectra or the sputtered and cleaved samples were measured. The results are displayed in Fig. 2. The spectrum of $\mathrm{Cu} \mathrm{L}_{3} \mathrm{M}_{45} \mathrm{M}_{45}$ XAES for the cleaved sample correlate with the signals from a oxide $\left(\mathrm{Cu}^{+}\left(\mathrm{Cu} 2 \mathrm{p}_{3 / 2}\right.\right.$ : 916.2 eV)), whereas the spectrum for the sputtered sample show the presence of metallic copper $\left(\mathrm{Cu}^{0}\left(\mathrm{Cu} 2 \mathrm{p}_{3 / 2}\right.\right.$ : $918.6 \mathrm{eV}))^{(13)}$. These results suggest that most of copper ions in this glass are reduced to the metallic state by argon-ion bombardment.

Mo 3d XPS spectra from the glasses bombarded by ions and cleaved in air, are given in Figs. 3(a) and (b), respectively. The Mo $3 \mathrm{~d}_{5 / 2}$ and Mo $3 \mathrm{~d}_{3 / 2}$ peaks are located at $232.3 \pm 0.3$ and $235.1 \pm 0.3 \mathrm{eV}$ in the cleaved sample, respectively, almost consistent with the binding energies of $\mathrm{Mo}^{6+}$ in $\mathrm{MoO}_{3}$. Thus, most of the molybdenum in this glass is present as $\mathrm{Mo}^{6+}$. Additional Mo $3 \mathrm{~d}_{5 / 2}$ peak at $229.3 \mathrm{eV}$ and $\mathrm{Mo} 3 \mathrm{~d}_{3 / 2}$ peak at $232.5 \mathrm{eV}$, comparable to the binding energies of $\mathrm{Mo}^{4+}$ in $\mathrm{MoO}_{2}$, appears after bombardment. This suggests that a significant amount of $\mathrm{Mo}^{4+}$ ions are formed on the surface of this glass by argon-ion bombardment, and the degree of reduction of molybdenum ions is comparable with the case of copper ion.

Figures 4(a) and (b) show I 3d XPS spectra from the sample bombarded by argon ions and cleaved in air, respectively. The I $3 \mathrm{~d}_{5 / 2}$ and $\mathrm{I} 3 \mathrm{~d}_{3 / 2}$ peaks are located at $619.7 \pm 0.3$ and $631.9 \pm 0.3 \mathrm{eV}$, respectively, in both cases. O 1s XPS spectra from the ion-bombarded and cleaved glass are given in Figs. 5(a) and (b), respectively. Again, the main peak position located at $530.3 \pm 0.3 \mathrm{eV}$ is not affected by the ion bombardment, although the shape of the peak is somewhat affected by ion bombardment. Thus, although the chemical state of these anions

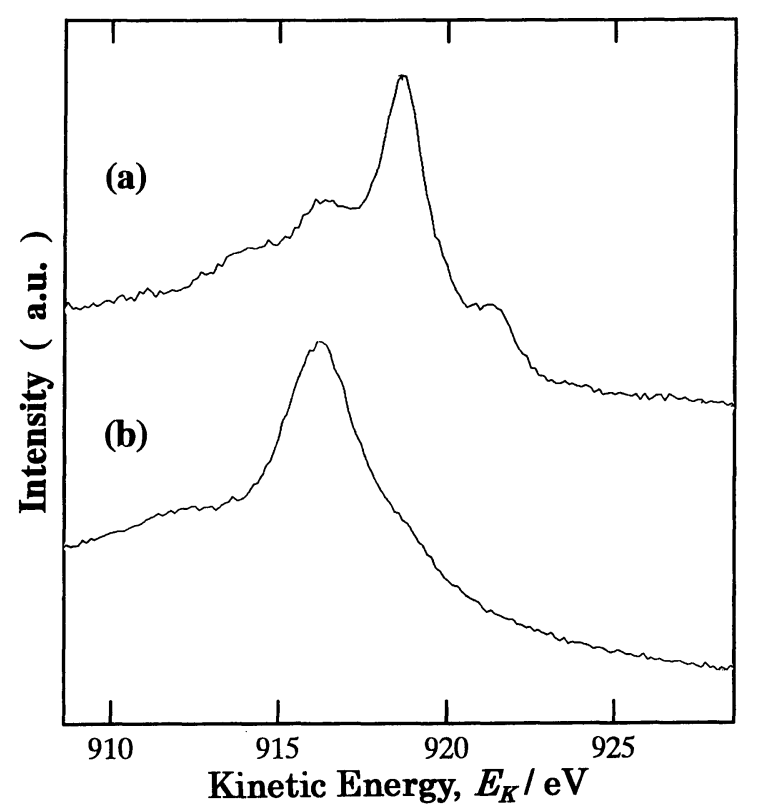

Fig. $2 \mathrm{Cu} \mathrm{L}_{3} \mathrm{M}_{45} \mathrm{M}_{45}$ XAES spectra of the $(\mathrm{CuI})_{0.3}\left(\mathrm{Cu}_{2} \mathrm{O}\right)_{0.35}\left(\mathrm{MoO}_{3}\right)_{0.35}$ glass (a) bombarded by argon ions, and (b) cleaved in air. 


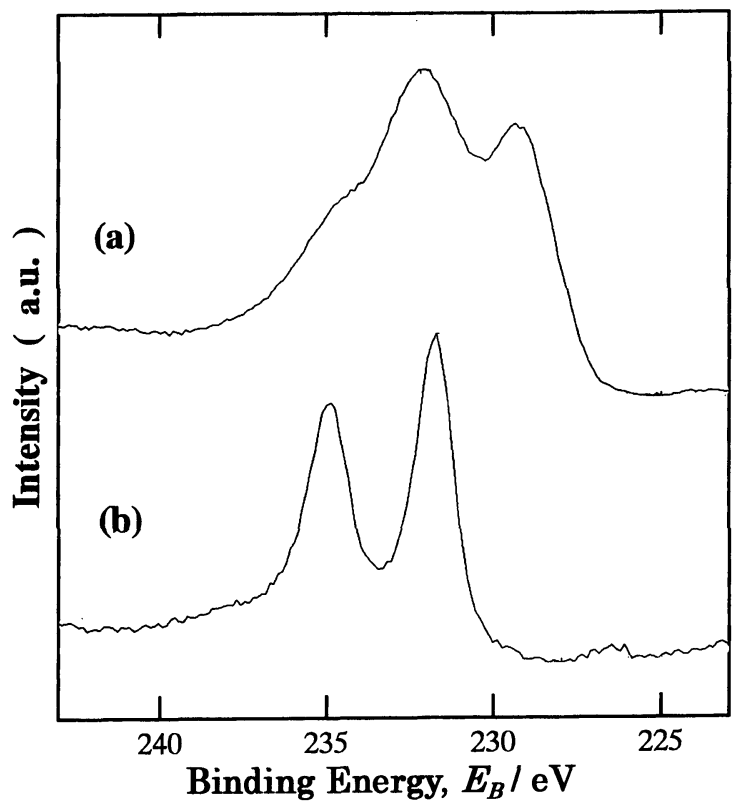

Fig. 3 Mo 3d XPS spectra of the $(\mathrm{CuI})_{0.3}\left(\mathrm{Cu}_{2} \mathrm{O}\right)_{0.35}\left(\mathrm{MoO}_{3}\right)_{0.35}$ glass (a) bombarded by argon ions, and (b) cleaved in air.

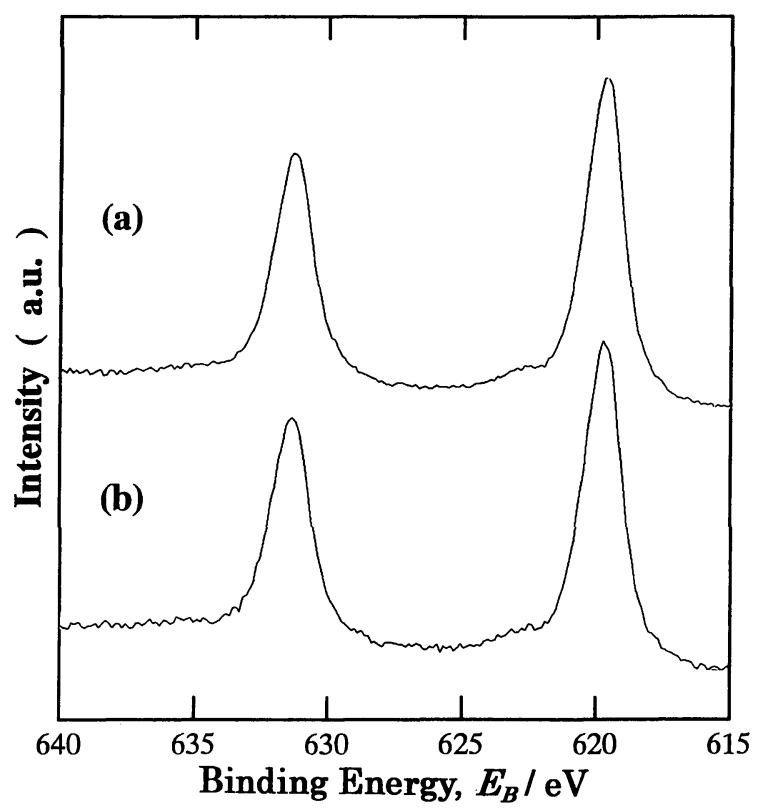

Fig. 4 I 3d XPS spectra of the $(\mathrm{CuI})_{0.3}\left(\mathrm{Cu}_{2} \mathrm{O}\right)_{0.35}\left(\mathrm{MoO}_{3}\right)_{0.35}$ glass (a) bombarded by argon ions, and (b) cleaved in air.

in the surface are unchanged by the argon-ion bombardment, other effects such as change in composition need to be considered.

The surface composition of the samples was estimated from the spectra using sensitivity factors of elements. The surface concentration of the cleaved sample was $34 \% \mathrm{Cu}, 46 \% \mathrm{O}, 8 \% \mathrm{Mo}$ and $12 \% \mathrm{I}$, which is nearly the bulk composition, while the surface concentration of a bombarded sample was $39 \% \mathrm{Cu}, 19 \% \mathrm{Mo}, 39 \% \mathrm{O}$ and $3 \%$ I. These results indicate that significant preferential sputtering of oxygen and iodine takes place during ion bombardment. The imbalance between cations and an-

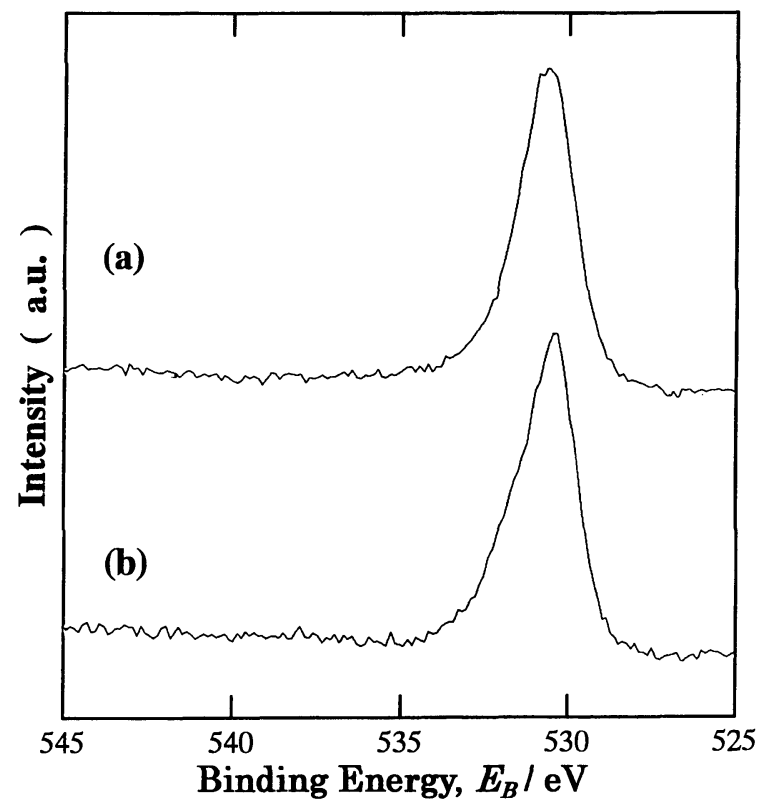

Fig. $5 \mathrm{O} 1 \mathrm{~s}$ XPS spectra of the $(\mathrm{CuI})_{0.3}\left(\mathrm{Cu}_{2} \mathrm{O}\right)_{0.35}\left(\mathrm{MoO}_{3}\right)_{0.35}$ glass (a) bombarded by argon ions, and (b) cleaved in air.

ions induced by the preferential sputtering may be responsible for reduction of copper and molybdenum on the surface of this glass, as shown in Figs. 2 and 3, respectively.

\section{Effect of aging on surface concentration}

Figures 6(a) and (b) show wide 2p XPS spectra from the glass $(\mathrm{CuI})_{0.3}\left(\mathrm{Cu}_{2} \mathrm{O}\right)_{0.35}\left(\mathrm{MoO}_{3}\right)_{0.35}$ just after cleavage in air, and after aging in air for $6000 \mathrm{~s}$, respectively. These spectra clearly show significant changes in the surface concentration with aging. The Mo $3 \mathrm{~d}$ and I $3 \mathrm{~d}$ XPS peaks and the others related to Mo and I decrease considerably on aging, whereas the peaks associated with copper show a relative increase. These facts indicate that copper is enriched on the surface during aging at room temperature. The driving force for the copper enrichment is probably associated with changes in surface energy by composition of the surface layer ${ }^{(14)}$, since an increase in the oxygen concentration suggesting oxidation and a significant change in the state of copper $\left(e . g . \mathrm{Cu}^{+}\right.$ to $\mathrm{Cu}^{2+}$ ) by aging was not observed in XPS spectra.

In order to analyze the kinetics of the aging process, changes in the surface concentration of copper, molybdenum, iodine and oxygen have been measured as a function of time. The results are plotted as a function of a square root of aging time after cleavage of the sample in Fig. 7. The concentration is calculated simply using sensitivity factors for elements to follow the relative changes in the surface concentration of the constituent elements. In spite of the simple assumptions used for quantitative estimation, systematic increases in the copper concentration and decreases in the molybdenum and iodine concentration with aging time are observed. Although the oxygen concentration shows a slight decrease with increasing time, the decrement is too small to warrant discussion. The aging behavior is assisted by the fast ion 


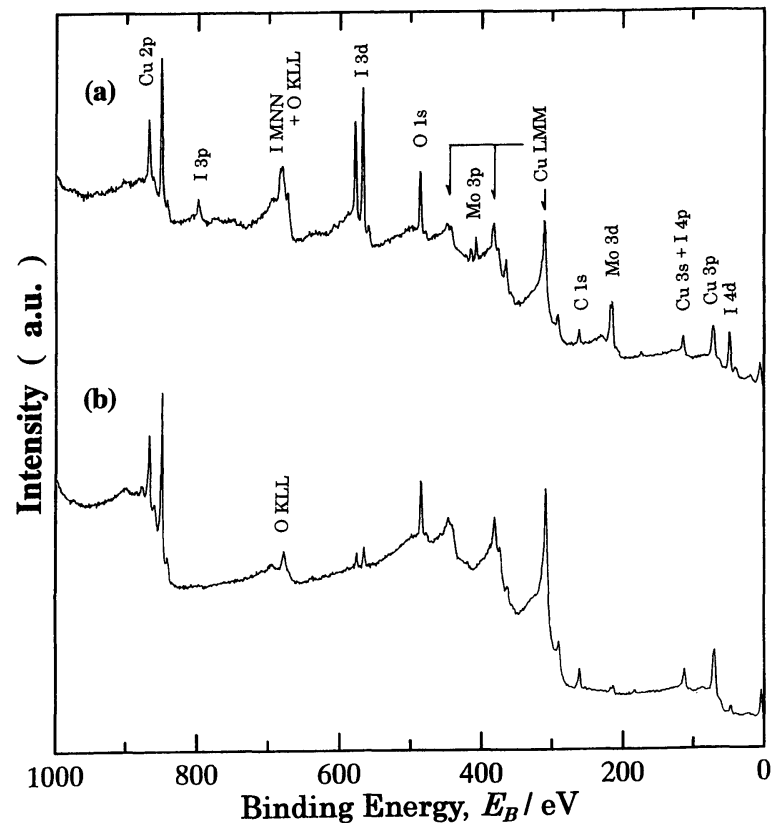

Fig. 6 Wide XPS spectra of the $(\mathrm{CuI})_{0.3}\left(\mathrm{Cu}_{2} \mathrm{O}\right)_{0.35}\left(\mathrm{MoO}_{3}\right)_{0.35}$ glass (a) cleaved in air, and (b) aged at room temperature for $6000 \mathrm{~s}$.

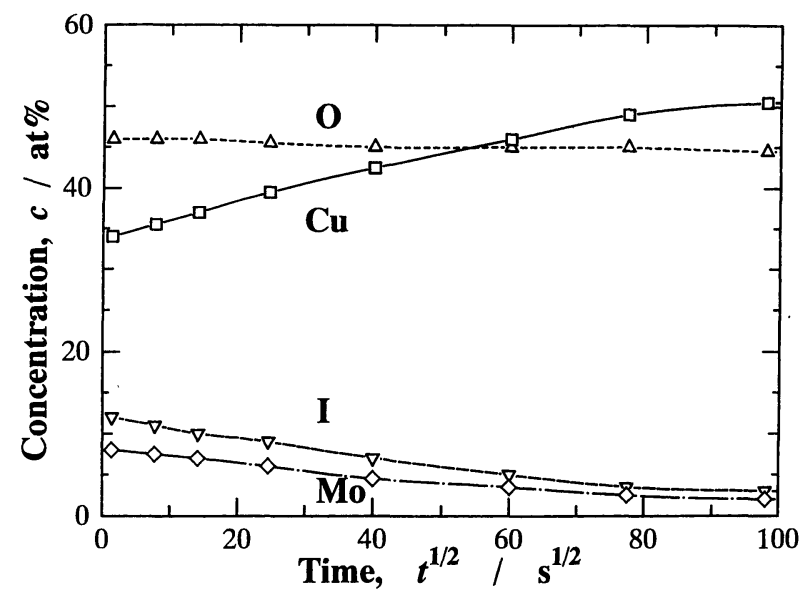

Fig. 7 Changes in the surface concentration of $\mathrm{Cu}, \mathrm{Mo}$, I and $\mathrm{O}$ with aging time at $295 \mathrm{~K}$.

transport in the glass ${ }^{(5)}$. The isothermal enhancement of surface concentration of copper in the glass shown in Fig. 7 can be analyzed by a method, analogous to that used for aging processes. If this process is considered as the surface segregation, the segregation kinetics can described mathematically ${ }^{(15)}$. The equation for the surface concentration $C_{\mathrm{s}}$ in the early stage is given by,

$$
C_{\mathrm{s}}=C_{0}\left[1+(2 / a)(D t / \pi)^{1 / 2}\right]
$$

where $C_{0}$ is the bulk concentration, $a$ the segregated layer thickness, $D$ the diffusion thickness and $t$ time $^{(16)}$. If the segregated layer is assumed to be $0.2 \mathrm{~nm}$, being nearly the diameter of copper ion, one can obtain a value of $0.8 \times 10^{-23} \mathrm{~m}^{2} \cdot \mathrm{s}^{-1}$ for the diffusion coefficient at $293 \mathrm{~K}$ and $1.2 \times 10^{-23} \mathrm{~m}^{2} \cdot \mathrm{s}^{-1}$ at $295 \mathrm{~K}$, using eq. (1). These values are much higher than the diffusivity of copper in

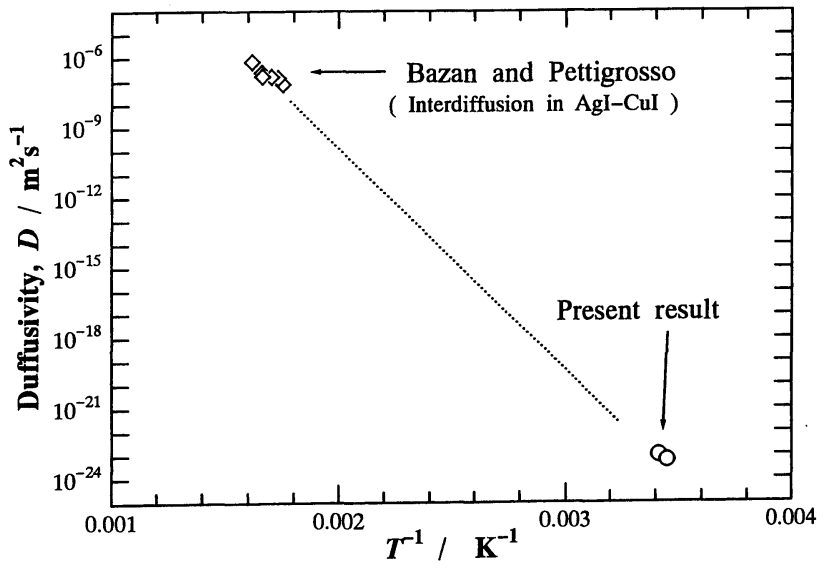

Fig. 8 Arrhenius plot of diffusion coefficient of copper in the glass $(\mathrm{CuI})_{0.3}\left(\mathrm{Cu}_{2} \mathrm{O}\right)_{0.35}\left(\mathrm{MoO}_{3}\right)_{0.35}$, together with interdiffusion coefficients in the previous work ${ }^{(5)}$.

pure copper at room temperature, which is estimated to be of the order of $10^{-43} \mathrm{~m}^{2} \cdot \mathrm{s}^{-1}$ by extrapolation of high temperature data ${ }^{(17)}$. Therefore, the high diffusivity of copper in the glass is related to the characteristic structure of the glass. The local environment of part of the $\mathrm{Cu}^{+}$ions in the $\mathrm{CuI}-\mathrm{Cu}_{2} \mathrm{O}-\mathrm{MoO}_{3}$ glass is similar to that in molten $\mathrm{CuI}^{\left({ }^{(9)}\right.}$. In addition, interdiffusion coefficients obtained at about $600 \mathrm{~K}$ in high conductivity system AgI$\mathrm{CuI}{ }^{(5)}$ may be compared with this present results. The temperature dependence of their values is shown in Fig. 8. The both sets of data were measured by different methods, in different temperature ranges. Nevertheless, the correspondence between two sets of data is reasonable, since the fast diffusion of copper ions is involved in both the cases.

\section{Concluding Remarks}

XPS spectra were used for characterizing the influence of argon-ion bombardment and aging at room temperature on the surface concentration of different species in the glass with the composition $(\mathrm{CuI})_{0.3}\left(\mathrm{Cu}_{2} \mathrm{O}\right)_{0.35^{-}}$ $\left(\mathrm{MoO}_{3}\right)_{0.35}$. It is found that:

(1) Argon-ion bombardment induces reduction of copper and molybdenum ions at the surface of the glass, $\mathrm{Cu}^{2+}$ to $\mathrm{Cu}^{0}$ and $\mathrm{Mo}^{6+}$ to $\mathrm{Mo}^{4+}$. The chemical state of iodine and oxygen is not significantly altered. The chemical changes associated with copper and molybdenum may be explained by the imbalance between cations and anions induced by preferential sputtering of iodine and oxygen.

(2) With aging time at room temperature, the concentration of copper at the surface increases, whereas the concentrations of molybdenum and iodine decrease. This may result from the fast diffusion of copper ions in the glass. From the study of the enrichment process of copper to the surface as a function of time, the diffusion coefficient of copper at room temperature was estimated to be of the order of $10^{-23} \mathrm{~m}^{2} \cdot \mathrm{s}^{-1}$. 


\section{Acknowledgments}

The authors are grateful to Mr. T. Sato and Mr. M. Ito for help in XPS.

\section{REFERENCES}

(1) H. L. Tuller, D. P. Button and D. R. Uhlmann: J. Non-cryst. Solids, 40 (1980), 93.

(2) J. L. Souquet: Solid State Ionics, 5 (1981), 77.

(3) T. Minami: J. Non-cryst. Solids, 56 (1983), 15.

(4) M. K. P. Seydei and S. A. Suthanthiraraj: J. Mater. Sci., 28 (1993), 3519.

(5) J. C. Bazan and R. S. Pettigroso: J. Mater. Sci., 31 (1996), 4077.

(6) K. Ihara and H. Okazaki: J. Phys. Condens. Matter, 9 (1997), 1477.

(7) N. Machida, M. Chusho and T. Minami: J. Non-cryst. Solids, 101 (1988), 70.

(8) T. Minami and N. Machida: Mat. Chem. Phys., 23 (1989), 784.
(9) M. Saito, K. Sugiyama, E. Matsubara, K. T. Jacob and Y. Waseda: Mater. Trans. JIM, 36 (1995), 1434.

(10) S. Suzuki, M. Oku and Y. Waseda: Surf. Interface Anal., 25 (1997), 161.

(11) S. Poulston, P. M. Parlett, P. Stone and M. Bowker: Surf. Interface Anal., 24 (1996), 811.

(12) S. Suzuki, Y. Ishikawa, N. Isshiki and Y. Waseda: Mater. Trans., JIM, 38 (1997), 1004.

(13) J. F. Moudler, W. F. Stickle, P. E. Sobol and K. Bomben: X-ray photoelectron spectroscopy, Physical Electronics, Minnesota, (1993), p. 219.

(14) P. Wynblatt and R. C. Ku: Interfacial Segregation, ed. by W. C. Johnson and J. M. Blakely, American Society for Metals, Ohio, (1979), p. 115

(15) D. McLean: Grain Boundaries in Metals, Oxford University Press, London, (1957), p. 116.

(16) G. N. van Wyk and W. D. Roos: Appl. Surf. Sci., 26 (1986), 317.

(17) R. J. Rothmann and N. L. Peterson: Phys. Stat. Solidi, 35 (1969), 305. 